\title{
ANALISIS KUALITAS TAHU TAKWA \\ DENGAN PENDEKATAN GOOD MANUFACTURING PRACTICES (GMP) DI INDUSTRI RUMAH TANGGA
}

\author{
Desi Listianingsih ${ }^{1}$, R. Azizah ${ }^{2}$ \\ ${ }^{1,2}$ Departemen Kesehatan Lingkungan, \\ Fakultas Kesehatan Masyarakat, Universitas Airlangga \\ Alamat korespondensi: Desi Listianingsih \\ E-mail: desilistianingsih@gmail.com
}

\begin{abstract}
The production process of knowing the traditional poultry requires a supervisory system with Good Manufacturing Practices (GMP) approach as stipulated in Regulation of BPOM Head of 2012 on Good Food Making. The quality of tofu produced by a domestic industry must be in accordance with Indonesian National Standard (SNI) 01-3142-1998 about the quality of tofu so that the products know that piety produced safe. This study aims to analyze the quality of know-how with the approach of Good Manufacturing Practices (GMP) and consumer attitudes toward tofu products in one household industry in Kediri. This research was descriptive with cross sectional approach. Aspects of GMP examined were the location and environment of production, buildings and facilities, production equipment, water supply or water supply facilities, hygiene and sanitation facilities and activities, storage, process control, food labeling, supervision by persons responsible, product recall, record and documentation, and employee training, and see the quality of the IRT. The results of the assessment of the implementation of GMP on IRT know this pardon of 59.67\%, included in the category of poor assessment. Therefore, it was necessary to improve the production process from the IRT to know piety against the unfavorable aspects, such as facilities and hygiene and sanitation activities, maintenance and hygiene and sanitation programs, storage, supervision by the responsible person, and recording and documentation, so that aspects it complies with the standards and produces quality tofu according to the standard.
\end{abstract}

Keywords: quality of tofu, Good Manufacturing Practices (GMP), production process, consumer attitude

\begin{abstract}
ABSTRAK
Proses produksi tahu takwa yang masih tradisional memerlukan sistem pengawasan dengan pendekatan Good Manufacturing Practices (GMP) yang diatur dalam Peraturan Kepala BPOM Tahun 2012 tentang Cara Pembuatan Pangan yang Baik. Kualitas tahu yang dihasilkan oleh suatu industri rumah tangga harus sesuai dengan Standar Nasional Indonesia (SNI) 01-3142-1998 tentang kualitas tahu agar produk tahu takwa yang diproduksi aman. Penelitian ini bertujuan untuk menganalisis kualitas tahu takwa dengan pendekatan Good Manufacturing Practices (GMP) dan sikap konsumen terhadap produk tahu takwa di salah satu industri rumah tangga di Kediri. Penelitian ini bersifat deskriptif dengan pendekatan cross sectional. Aspek GMP yang diteliti adalah lokasi dan lingkungan produksi, bangunan dan fasilitas, peralatan produksi, suplai air atau sarana penyediaan air, fasilitas dan kegiatan higiene dan sanitasi, penyimpanan, pengendalian proses, pelabelan pangan, pengawasan oleh penanggungjawab, penarikan produk, pencatatan dan dokumentasi, dan pelatihan karyawan, serta melihat kualitas yang dihasilkan oleh IRT. Hasil penilaian penerapan GMP pada IRT tahu takwa ini sebesar $59,67 \%$, termasuk dalam kategori penilaian kurang baik. Sehingga, perlu adanya perbaikan proses produksi dari pihak IRT tahu takwa terhadap aspek-aspek yang kurang baik, yaitu fasilitas dan kegiatan higiene dan sanitasi, pemeliharaan dan program higiene dan sanitasi, penyimpanan, pengawasan oleh penanggungjawab, dan pencatatan dan dokumentasi, sehingga aspek-aspek tersebut sesuai dengan standar dan menghasilkan kualitas tahu sesuai dengan standar.
\end{abstract}

Kata kunci: kualitas tahu takwa, good manufacturing practices (GMP), proses produksi 


\section{PENDAHULUAN}

Pangan merupakan kebutuhan primer yang memerlukan perhatian karena pangan yang tidak aman dapat membahayakan kesehatan masyarakat. Menurut World Health Organization (WHO), banyak orang yang sakit dan meninggal dikarenakan makanan yang tidak aman, sekitar lebih dari 200 jenis penyakit disebabkan oleh pencemaran makanan, sehingga diperlukan cara perlakuan makanan yang aman dan bermutu.

Berdasarkan Laporan dari Badan Pengawas Obat dan Makanan (BPOM) pada tahun 2014, penyebab keracunan berdasarkan jenis makanan tertinggi adalah masakan rumah tangga sebanyak 17 kejadian (36\%), sedangkan 13 kejadian (28\%) pangan jasa boga, 12 kejadian $(26 \%)$ pangan jajanan, dan 5 kejadian (11\%) pangan olahan, di mana umumnya pangan jajanan dan pangan jasa boga dihasilkan oleh industri pangan siap saji. Data BPOM tentang kelompok penyebab keracunan tertinggi di Indonesia pada tahun 2016 juga diakibatkan keracunan oleh konsumsi makanan.

Kota Kediri merupakan salah satu kota penghasil makanan dengan beberapa produk unggulan yang dihasilkan. Berdasarkan data dari Pemerintah Kota Kediri pada Tahun 2016, tahu merupakan salah satu produk unggulan di Kota Kediri. Salah satu tahu yang terbanyak produksi dan paling diminati adalah tahu takwa dengan ciri khas berwarna kuning, sehingga menjadi daya tarik tersendiri bagi konsumen. Berdasarkan data dari Dinas Perindustrian dan Perdagangan Kota Kediri (Disperindag) pada tahun 2013, jenis usaha dengan jumlah unit usaha terbanyak adalah usaha tahu sebanyak 121 unit.

Tahu takwa merupakan salah satu jenis tahu yang menarik karena berwarna kuning. Warna tersebut merupakan daya tarik bagi konsumen dalam membeli tahu. Berdasarkan penelitian G. Nainggolan-
Sihombing (2001), beberapa tahu kuning yang dijual di Jakarta mengandung bahan pewarna non-pangan. Makanan dan minuman yang tidak berkualitas dan tercemar dapat menimbulkan foodborne disease. Foodborne disease disebabkan karena makanan dan minuman terkontaminasi oleh mikroorganisme patogen. Mikroorganisme yang sering menjadi penyebab foodborne disease adalah Salmonella dan E. coli.

Industri rumah tangga (IRT) yang akan diteliti merupakan salah satu industri yang memproduksi tahu takwa di Kediri. IRT ini terletak di pusat Kediri, yang merupakan jalur penghubung antar kota yaitu sebagai lokasi penelitian. IRT ini merupakan salah satu IRT dari beberapa IRT tahu takwa yang memproduksi tahu secara tradisional. IRT tersebut dipilih untuk penelitian karena mempunyai kapasitas produksi terbanyak di Kediri atau paling banyak diminati oleh konsumen baik pendatang maupun masyarakat sekitar yang berkunjung ke Kediri.

Menurut Rudiyanto (2016), guna menghasilkan produk pangan yang aman dan layak konsumsi, maka terdapat pedoman atau panduan yang mensyaratkan produsen makanan untuk menerapkan Cara Produksi Pangan yang Baik (CPPB) bagi industri rumah tangga atau disebut dengan GMP.

Berdasarkan identifikasi masalah, penelitian ini dibatasi pada penerapan GMP. Penelitian ini mencakup tentang penerapan proses produksi pada produk tahu takwa apakah sudah sesuai dengan prinsip dasar GMP.

Berdasarkan data dari studi pendahuluan, IRT yang di salah satu IRT di Kediri ini merupakan salah satu IRT yang memproduksi tahu secara tradisional. Proses produksi tahu yang masih tradisional memerlukan sistem pengawasan sesuai dengan Peraturan Kepala BPOM Tahun 2012 tentang Cara Pembuatan Pangan yang Baik serta tahu yang dihasilkan sesuai dengan Standar Nasional Indonesia (SNI) 01-3142-1998 
tentang tahu. (SNI) 01-3142-1998 tentang tahu meliputi kualitas fisik (bau, warna, dan rasa), kualitas mikrobiologi (E. coli dan Salmonella), dan kualitas kimia (bahan tanbahan pangan pewarna Tartrazine CI 19140).

\section{METODE PENELITIAN}

Jenis penelitian ini adalah observasional. Berdasarkan sifatnya, penelitian ini bersifat deskriptif. Sedangkan berdasarkan waktunya, penelitian ini bersifat cross sectional.

Populasi pada penelitian ini meliputi industri rumah tangga, 250 gram produk tahu takwa, dan $250 \mathrm{~mL}$ air bersih. Penelitian ini juga melibatkan karyawan sebagai penjamah produk yang berjumlah 15 orang.

Sampel penelitian ini meliputi: sampel tahu takwa 250 gram diambil dari hasil produksi IRT tahu takwa di salah satu IRT tahu takwa di Kediri dengan cara diiris membujur agar mendapatkan sampel dari setiap bagian. Pengambilan sampel dilakukan secara simple random sampling untuk diteliti kualitas bakteriologis terkait keberadaan Escherichia coli dan Salmonella, kualitas kimia (Bahan Tambahan Pangan/BTP), dan kualitas fisik yang meliputi: bau, rasa, dan warna.

Penelitian ini dilakukan di lokasi produksi di salah satu IRT tahu takwa di Kediri. Lokasi ini dipilih sebagai penelitian karena mempunyai jumlah produksi dan penjamah makanan paling banyak dibandingkan IRT tahu takwa lainnya. Penelitian ini dilakukan pada Bulan Mei 2018.

Variabel yang diteliti untuk industri rumah tangga, antara lain: lokasi dan lingkungan produksi, bangunan dan fasilitas, peralatan produksi, suplai air atau sarana penyediaan air, fasilitas dan kegiatan higiene dan sanitasi, penyimpanan, pengendalian proses, pelabelan pangan, pengawasan oleh penanggungjawab, penarikan produk, pencatatan dan dokumentasi, dan pelatihan karyawan. Variabel kualitas tahu takwa, antara lain: kualitas fisik (warna, bau, dan rasa), mikrobiologis (E. coli), dan kimia (pewarna kuning pada tahu).

Data dikumpulkan dengan teknik antara lain, observasi, kuesioner, pengujian laboratorium, dan dokumen dari pihak IRT.

Sampel air bersih sebanyak $250 \mathrm{ml}$ dilakukan secara simple random sampling yang digunakan untuk proses produksi tahu takwa di salah satu IRT tahu takwa di Kediri untuk diteliti keberadaan koliform. Sampel tahu takwa dan air bersih dimasukkan ke dalam coolbox dan dibawa ke Laboratorium Kesehatan untuk dilakukan pengujian. Sampel karyawan sebagai penjamah makanan diambil guna mengetahui higiene penjamah makanan. Sampel karyawan diperoleh dengan mengambil seluruh populasi dari karyawan, yaitu sebanyak 15 orang.

\section{HASIL}

IRT tahu takwa ini merupakan salah satu industri yang memproduksi tahu takwa di Kediri. IRT ini terletak di pusat Kediri, yang merupakan jalur penghubung antar kota yaitu sebagai lokasi penelitian. IRT ini merupakan salah satu IRT dari beberapa IRT tahu takwa yang memproduksi tahu secara tradisional. IRT tahu takwa ini sudah berdiri sejak Tahun 1993. Pemilik memulai usaha tahu takwa ini berawal dari memproduksi tahu yang hanya dijual di pasar saja, apabila tahu telah habis maka pulang dan memproduksi lagi. Kemudian pemilik mengikuti program Usaha Kecil Menengah (UKM) yang diadakan oleh Pemerintah Kabupaten Kediri pada Tahun 2007. Setelah itu, usaha tahu takwa ini semakin berkembang sampai kini membuka usaha pertokoan oleh-oleh tahu takwa yang berlokasi strategis, yang jaraknya 3,5 km saja dari Kantor Kabupaten Kediri.

Luas lokasi produksi tahu takwa ini yaitu $70 \mathrm{~m}^{2}$. Proses produksi dilakukan di rumah Bapak Gatot sebagai pemilik usaha 
tahu takwa ini. Waktu proses produksi dimulai pada pukul 06.00 WIB sampai pukul 13.00 WIB. Apabila permintaan pasar lebih banyak, maka bisa sampai pukul 15.00 WIB.

Bahan baku pembuatan tahu takwa diperoleh melalui produsen kedelai yang didatangkan langsung dari pasar ke lokasi produksi setiap harinya. Selain itu, bahan baku lain seperti garam dan kunyit juga diperoleh dari produsen di pasar. Kedelai yang dibutuhkan untuk produksi adalah 5 kwintal untuk sekitar 21 masakan per hari. Sekali proses produksi, membutuhkan ratarata $12 \mathrm{~kg}$ kedelai. Kunyit bahan baku untuk pewarna alami kuning dibutuhkan rata-rata $2 \mathrm{~kg}$ per hari. Garam dibutuhkan lebih kurang $1 \mathrm{~kg}$ setiap harinya.

Hasil produksi tahu takwa dijual di toko tahu takwa dengan merk ini sebagai pusat oleh-oleh khas Kediri yang terdapat tidak jauh dari lokasi produksi. Tidak hanya itu, tahu takwa ini dijual kepada agen tahu takwa yang berjumlah 15 . Biasanya, tahu takwa diambil oleh agen atau diantar oleh distributor dari lokasi ke tempat agen berjualan. Tidak setiap hari hal tersebut dilakukan, hanya dilakukan pada saat stok sudah habis saja.

Proses produksi tahu takwa ini diproduksi oleh 15 orang karyawan dengan jumlah 10 laki-laki dan 5 perempuan. Laki-laki yang bertugas pada bagian produksi, sedangkan sisanya yaitu perempuan bertugas mengemas produk tahu takwa yang sudah jadi. Masingmasing karyawan dari 9 karyawan laki-laki bekerja pada pada 8 tahap proses produksi, yaitu penimbangan penyortiran dan pencucian bahan baku, perendaman dan pencucian bahan baku, pengayakan, penggilingan, perebusan dan pemberian cuka, penyaringan dan pencetakan, dan pewarnaan, serta pengemasan. Sedangkan 1 sisanya bertugas secara fleksibel. Namun, seluruh karyawan tetap harus bisa melakukan semua tahapan proses produksi, sehingga pegawai yang bekerja tidak tetap pada satu tahapan saja.
Berdasarkan hasil observasi dengan menggunakan standar Peraturan Kepala Badan Pengawas Obat dan Makanan No. HK.03.1.23.04.12.2206 Tahun 2012 Tentang Cara Produksi Pangan yang Baik untuk Industri Rumah Tangga, diketahui skor penilaian IRT tahu takwa di salah satu IRT tahu takwa di Kediri ini adalah sebesar 179 dari jumlah total skor 300 yang harus diperoleh. Presentase aspek GMP pada IRT tahu takwa ini adalah sebesar: $179 / 300 \times 100 \%=59,67 \%$, termasuk dalam kategori kurang baik.

Hasil penilaian menunjukkan bahwa aspek lokasi dan lingkungan produksi termasuk dalam kategori cukup baik dengan perolehan skor 10 dari 15 poin $(66,67 \%)$. Hasil penilaian menunjukkan bahwa aspek bangunan dan fasilitas termasuk dalam kategori cukup baik dengan perolehan skor 14 dari 21 poin $(66,67 \%)$. Hasil penilaian menunjukkan bahwa aspek peralatan produksi termasuk dalam kategori cukup baik dengan perolehan skor 11 dari 21 poin $(52,38 \%)$. Hasil penilaian menunjukkan bahwa aspek suplai air atau sarana penyediaan air termasuk dalam kategori cukup baik dengan perolehan skor 24 dari 24 poin $(100 \%)$. Hasil penilaian menunjukkan bahwa aspek fasilitas dan kegiatan higiene dan sanitasi termasuk dalam kategori kurang baik dengan perolehan skor 12 dari 30 poin $(40 \%)$. Hasil penilaian menunjukkan bahwa aspek kesehatan dan higiene karyawan termasuk dalam kategori cukup baik dengan perolehan skor 30 dari 45 poin $(66,67 \%)$. Hasil penilaian menunjukkan bahwa aspek pemeliharaan dan program higiene dan sanitasi termasuk dalam kategori kurang baik dengan perolehan skor 9 dari 27 poin $(33,33 \%)$. Hasil penilaian menunjukkan bahwa aspek penyimpanan termasuk dalam kategori kurang baik dengan perolehan skor 10 dari 21 poin $(47,61 \%)$. Hasil penilaian menunjukkan bahwa aspek pengendalian proses termasuk dalam kategori cukup baik dengan perolehan skor 16 dari 24 poin $(66,67 \%)$. Hasil penilaian menunjukkan 
bahwa aspek pelabelan pangan termasuk dalam kategori cukup baik dengan perolehan skor 12 dari 18 poin $(40 \%)$. Hasil penilaian menunjukkan bahwa aspek pengawasan oleh penanggungjawab termasuk dalam kategori kurang baik dengan perolehan skor 5 dari 15 poin $(33,33 \%)$. Hasil penilaian menunjukkan bahwa aspek penarikan produk termasuk dalam kategori baik dengan perolehan skor 12 dari 12 poin (100\%). Hasil penilaian menunjukkan bahwa aspek pencatatan dan dokumentasi termasuk dalam kategori kurang baik dengan perolehan skor 4 dari 12 poin $(33,33 \%)$. Hasil penilaian menunjukkan bahwa aspek pelatihan karyawan termasuk dalam kategori baik (100\%).

Berdasarkan Tabel 1. di atas dapat diketahui bahwa kualitas fisik tahu takwa IRT tahu takwa di salah satu IRT tahu takwa di Kediri sudah sesuai dengan standar, yaitu tidak berbau busuk, rasanya normal seperti tahu pada umumnya, dan warnanya kuning normal. Pengujian keberadaan mikrobiologis dilakukan di Laboratorium Kesehatan Surabaya. Hasil pengujian tersebut menunjukkan bahwa produk tahu takwa tersebut positif E. coli.

Tabel 1. Hasil Pemeriksaan Kualitas Tahu Takwa Berdasarkan SNI 01-31421998 tentang Kualitas Tahu

\begin{tabular}{|c|c|c|c|}
\hline Kualitas & Hasil & Memenuhi & Tidak \\
\hline \multicolumn{4}{|l|}{ Fisik: } \\
\hline Bau & $\begin{array}{l}\text { Tidak } \\
\text { berbau }\end{array}$ & V & - \\
\hline Warna & $\begin{array}{l}\text { Tidak } \\
\text { berwarna }\end{array}$ & V & - \\
\hline Rasa & $\begin{array}{l}\text { Tidak } \\
\text { berasa }\end{array}$ & V & - \\
\hline $\begin{array}{l}\text { Biologi: } \\
\text { E.coli }\end{array}$ & $\begin{array}{l}\text { E.coli: } \\
\text { positif }\end{array}$ & - & V \\
\hline $\begin{array}{l}\text { Salmonel } \\
\text { la }\end{array}$ & $\begin{array}{l}\text { Salmonel } \\
\text { la: } \\
\text { negatif }\end{array}$ & V & - \\
\hline $\begin{array}{l}\text { Kimia: } \\
\text { Tartrazin }\end{array}$ & Positif & - & V \\
\hline $\begin{array}{l}\mathrm{e} \\
19140\end{array}$ & & & \\
\hline
\end{tabular}

Kualitas kimia bahan tambahan pangan (BTP), berupa Tartrazine CI 19140 digunakan oleh IRT ini sebagai tambahan pewarna buatan pada tau takwa, namun tidak menggunakan takaran yang jelas sesuai dengan peraturan dari PERMENKES RI No. 722 Tahun 1988 tentang Bahan Tambahan Pangan adalah $70 \mu \mathrm{g} / \mathrm{mL}$ produk siap dikonsumsi untuk minuman atau makanan cair. Kesimpulan dari hasil pemeriksaan kualitas tahu adalah tidak memenuhi persyaratan SNI 01-31421998 tentang kualitas tahu.

\section{PEMBAHASAN}

IRT tahu takwa ini tidak menggunakan ukuran yang diperbolehkan untuk penggunaan pewarna Tartrazine CI 19140, hanya menggunakan perkiraan karyawan saja. Bahan baku lainnya, seperti kedelai, garam, kunyit, dan cuka sesuai dengan takaran dan dalam kondisi yang baik, serta tidak melebihi tanggal kadaluarsa. Menurut BPOM (2012), persyaratan bahan baku yang baik adalah kondisinya baik atau tidak rusak dantidak mengandung bahan berbahaya. Apabila menggunakan bahan tambahan pangan, maka harus sesuai dengan batas aman yang telah ditetapkan. Bahan baku merupakan syarat yang harus dipenuhi agar kualitas tahu takwa tetap terjaga.

Pencucian dan perendaman dilakukan dengan menggunakan air. Air bersih yang digunakan dalam proses ini berasal dari air bak penampungan yang telah dipakai untuk mencuci peralatan produksi. Pengayakan dilakukan untuk menghilangkan kotoran kedelai sebelum memasuki tahap penghancuran kedelai menjadi bubur kedelai. Pengayakan dilakukan secara langsung tanpa menggunakan sarung tangan. Menurut Wulandari (2012), Seharusnya penjamah makanan, yaitu karyawan menggunakan sarung tangan pada saat bersentuhan langsung dengan makanan. Penggunaan sarung tangan wajib dilakukan oleh setiap penjamah makanan untuk melindungi tahu 
terhadap kontaminasi dari tangan penjamah ke tahu.

Mesin penggilingan tahu pada tahap ini digunakan untuk menghaluskan biji kedelai menjadi bubur kedelai yang siap untuk dimasak dan dibuat tahu. Cat pada alat penggiling agak megelupas, sehingga kondisi mesin sedikit berkarat. Dalam proses perebusan atau pemasakan bubur tahu, karyawan tidak menggunkan sarung tangan sebagai pelindung makanan dari kontaminasi tubuh. Seharusnya penjamah makanan, yaitu karyawan menggunakan sarung tangan pada saat bersentuhan langsung dengan makanan. Kondisi peralatan yang digunakan untuk proses penyaringan dan pencetakan dalam kondisi baik, terbuat dari kayu berbentuk persegi, dan tidak berkarat, sehingga aman untuk digunakan. Namun, pencetakan tahu tidak dilakukan penjamah dengan menggunakan sarung tangan.

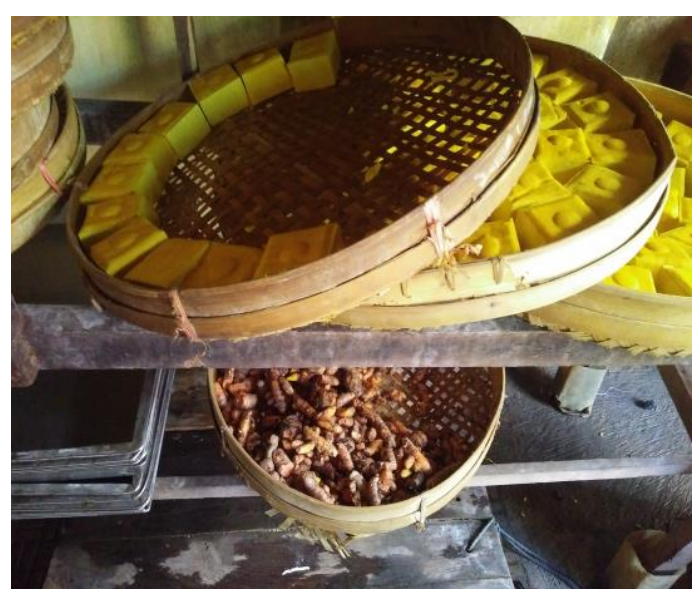

Gambar 1. Produk Tahu Takwa dengan Pewarna Kuning Kunyit dan Tartrazine CI 19140

Berdasarkan Gambar 1 dapat diketahui bahwa hasil produk tahu takwa oleh industri rumah tangga melalui proses pewarnaan menggunakan pewarna alami kunyit yang ditambahkan garam dan pewarna makanan Tartrazine CI 19140. Namun penggunaan pewarna Tartrazine CI 19140 tidak dilakukan dengan menggunakan takaran yang sudah ditetapkan. Pengemasan makanan dilakukan secara langsung tanpa menggunakan sarung tangan. Seharusnya penjamah makanan, yaitu karyawan menggunakan sarung tangan pada saat bersentuhan langsung dengan makanan (Wulandari, 2012). Rachmadia et al (2018) menyatakan bahwa jarak waktu antara proses pendiginan dengan pengemasan dapat mengakibatkan terjadinya kontaminasi pada makanan.

Lokasi IRT rata-rata basah karena air sehingga kotoran mudah membuat kotor lantai. Jarak IRT tahu takwa ini dengan TPS (Tempat Penampungan Sementara) lebih dari 100 meter. Kondisi lokasi tidak berbau. Lokasi IRT cukup sesuai dengan Peraturan Kepala BPOM Tahun 2012 tentang Cara Produksi Pangan yang Baik (CPPB), hanya saja untuk kebersihan perlu ditingkatkan. Menurut penelitian dari Nicolas dkk (2006), bahwa apabila lingkungan tidak dekat dengan sampah, maka tidak akan menimbulkan bau dan hewan pengganggu, seperti serangga dan lainnya. Bahan lantai adalah keramik, lantai rata, halus, dan licin, tetapi kuat dan mudah dibersihkan ke saluran pembuangan karena bentuknya yang sengaja dibuat miring ke arah saluran pembuangan. Hal tersebut sudah sesuai dengan Peraturan Kepala BPOM Tahun 2012. Dinding bangunan terbuat dari batubata yang disemen dan dilapisi cat. Namun cat pada dinding terlihat kotor dan beberapa bagian mulai mengelupas, sehingga tidak kedap air dan tidak mudah dibersihkan. Dinding yang kotor dapat mengakibatkan pencemaran atau kontaminasi silang pada makanan (Avita $e t$ $a l, 2015$ ). Tidak terdapat langit-langit pada IRT ini, tetapi atap. Atap terbuat dari asbes yang merupakan bahan tahan lama, tahan air dan tidak bocor, tidak mudah terkikis, dan bersih karena terlihat masih baru. Sehingga meminimalisir kontaminasi makanan dengan kotoran. Menurut BPOM (2012), desain atap yang baik akan mencegah adanya penumpukan debu, adanya lumut atau jamur yang tumbuh, dan tempat bersarangnya hama. Ventilasi atau jendela pada ruang produksi ada 6 sisi dengan ukuran masing-masing 30 x $30 \mathrm{~cm}$. 
Selain itu, terdapat ventilasi alami lainnya yaitu berasal dari pintu ruangan yang letakknya di belakang. Seluruh jendela dan pintu ruangan dalam keadaan terbuka. Hasil dari pengukuran pencahayaan dengan menggunakan luxmeter di ruang produksi yaitu sebesar 123,34 lux. Hasil pencahayaan yang ada di IRT tahu takwa tersebut belum memenuhi standar yang ada menurut Permenkes No.1096 Tahun 2011 Tentang Jasa Boga, yaitu sebesar 200 lux.

Pada peralatan produksi mesin penggilung tahu terdapat sedikit cat yang mengelupas, sehingga sedikit berkarat pada mesin penggilingan. Menurut Rudiyanto (2016), adanya karat menjadi sumber kontaminan pada makanan hasil produksi. Sehingga, perlu adanya proses pengecatan ulang pada mesin penggiling, agar mencegah terjadi kontaminasi pada tahu. Berdasarkan pengujian yang telah dilakukan, air yang digunakan untuk proses produksi tidak memenuhi standar air minum karena total koliform yang ada pada air sebesar lebih dari $1600 \mathrm{MPN} / 100$ mL. Berdasarkan Permenkes No.492 Tahun 2010 bahwa total koliform yang diperbolehkan ada pada air sebesar 0 MPN/ $100 \mathrm{ml}$. Karena jumlah fasilitas pada ruang produksi kurang. Tidak terdapat tempat cuci tangan atau wastafel pada ruang produksi tahu takwa, wastafel hanya tersedia di ruang produksi produk lain. Sedangkan keadaan toilet tidak cukup baik karena dinding dan lantai dan gayung toilet yang berlumut, pintu toilet yang sudah tidak layak pakai atau banyak bagian yang berlubang, tidak cukup air di toilet, tidak terdapat sabun cuci tangan, sehingga tidak nyaman untuk dipakai. Hal tersebut sesuai dengan teori Purnawijayanti (2001), bahwa karyawan sebagai penjamah makanan melakukan cuci tangan dengan sabun dan air mengalir untuk menghilangkan bakteri di tangan.

Pada IRT tahu takwa ini tidak terdapat SOP (Standar Operasional Prosedur) tentang perilaku dan penggunaan APD (Alat Pelindung Diri) pada saat proses produksi berlangsung, sehingga penjamah tidak memakai APD saat produksi tahu takwa. Kecuali menggunakan sepatu kerja berupa sepatu booth. Semua penjamah laki-laki tidak menggunakan baju atau pakaian kerja pada saat proses produksi berlangsung. Menurut Purnawijayanti (2001), penjamah makanan harus memakai pakaian kerja yang bersih dan setiap hari diganti agar mencegah adanya pencemaran makanan melalui penjamah. 3 dari 10 orang penjamah lakilaki yang mencuci sabun sebelum produksi dan 2 orang setelah proses produksi. Sedangkan perilaku mencuci tangan setelah dari toilet hanya dilakukan oleh 4 penjamah saja. Sesuai dengan penelitian Sari (2016), perilaku tidak mencuci tangan dengan menggunakan sabun menyebabkan kotoran dari tangan mencemari makanan. Sebanyak 4 penjamah perempuan selalu menggunakan alas kaki sandal bukan sepatu kerja, sedangkan 1 orang perempuan tidak pernah memakai alas kaki. Alas kaki yang dipakai oleh penjamah laki-laki pada saat proses produksi adalah bertujuan untuk menghindarkan diri dari kecelakaan kerja atau agar tidak terpeleset. Menurut Sari (2016), perilaku penjamah makanan dapat mempengaruhi kualitas produk pangan yang dihasilkan.

Penjamah melakukan pemeriksaan 3 bulan sekali, 5 penjamah 6 bulan sekali, dan 6 penjamah 1 tahun sekali. Menurut Purnawijayanti (2001), seharusnya penjamah makanan melakukan pemeriksaan kesehatan minimal 6 bulan sekali agar diketahui gangguan kesehatan pada penjamah makanan dan adanya pencegahan penularan penyakit dari penjamah ke makanan. Komponen yang kurang baik adalah pada kegiatan pembasmian serangga dan hewan pengganggu lainnya yang tidak dilakukan oleh pihak IRT. Menurut Koswara (2006), hama berupa serangga dan hewan pengganggu lainnya dapat berbahaya bagi berlngsungnya proses produksi karena dapat merusak bahan baku, fasilitas, dan menyebabkan penyakit. 
Bahan baku kunyit disimpan di wadah anyaman bambu yang tidak tertutup atau dibiarkan terbuka. Sesuai dengan penelitian oleh Wulandari (2012) bahwa adanya bakteri dipengaruhi oleh kelembapan, suhu, dan sanitasi dalam ruang yang mana bakteri tersebut dapat menyebabkan penyakit pada karyawan. Wadah dan pengemas hanya diletakkan di tempat yang tidak jauh dari tempat produksi tanpa dimasukkan di lemari atau ruangan khusus yang menghindarkan dari debu. Hal tersebut sesuai dengan penelitian Wulandari (2012), bahwa penyimpanan yang tidak baik dapat menyebabkan kontaminasi bakteri pada produk. Penyimpanan peralatan tidak diletakkan pada tempat yang tertutup atau memungkinkan kontaminasi dengan debu. Peralatan produksi seharusnya diletakkan pada tempat yang menghindarkan dari debu. Hal tersebut sesuai dengan penelitian Rudiyanto (2016), penyimpanan peralatan yang aman, yaitu menghindarkan dari kontaminasi dengan debu.

Pengendalian proses produksi yang sudah dilakukan di IRT tahu takwa di salah satu IRT tahu takwa di Kediri ini adalah penetapan spesifikasi bahan baku yang digunakan, yaitu kedelai, kunyit, garam, dan cuka, penetapan komposisi dan formulasi bahan dalam pembuatan adonan, penetapan cara produksi yang baku, dan penetapan jenis, ukuran, dan spesifikasi kemasan. Aspek pengendalian proses yang tidak dilakukan yaitu penetapan keterangan lengkap tentang produk. Tidak adanya keterangan tanggal bulan dan tahu produksi, tanggal bulan dan tahun kadaluarsa, dan berat bersih. Label pangan yang belum ada pada tahu takwa ini adalah tanggal bulan dan tahu produksi, tanggal bulan dan tahun kadaluarsa, dan berat bersih. Adanya label pada pangan bertujuan untuk memberi informasi pada konsumen. Menurut BPOM (2012), kemasan pada makanan seharusnya memberikan informasi yang jelas agar konsumen dapat lebih mudah untuk memperlakukan pangan.
Pemilik sebagai penanggungjawab tidak memiliki sertifikat penyuluhan keamanan pangan (Sertifikat PKP), pengawasan bahan, pengawasan proses, dan tindakan koreksi atau pengendalian. Namun, biasanya mahasiswa dari beberapa universitas pernah melakukan penyuluhan tentang higiene dan sanitasi karyawan. Selama ini tidak ada produk yang ditarik dari peredaran. Namun, pemilik IRT tahu takwa ini akan menarik produk tahu takwa dari peredaran apabila diduga menimbulkan penyakit atau keracunan. Tidak ada pencatatan dan dokumentasi yang dilakukan oleh IRT tahu takwa ini, yang meliputi penerimaan bahan baku, bahan tambahan pangan (BTP), dan bahan penolong sekurang-kurangnya memuat nama bahan, jumlah, tanggal pembelian, nama dan alamat pemasok.

Pemilik sudah pernah mengikuti penyuluhan tentang cara produksi pangan yang baik untuk industri rumah tangga di beberapa kesempatan, salah satunya adalah mengikuti program Usaha Kecil Menengah (UKM) yang diadakan oleh Pemerintah Kabupaten Kediri pada Tahun 2007. Perlunya pelatihan bagi penjamah adalah untuk meningkatkan pengetahuan penjamah tentang cara produksi makanan yang baik dan benar.

Hasil penelitian fisik, mikrobiologis, dan kimia yang telah dilakukan adalah produk tahu takwa dari IRT tahu takwa di salah satu IRT tahu takwa di Kediri telah memenuhi standar kualitas fisik, namun tidak memenuhi persyaratan secara mikrobiologis dan kimia. Hal tersebut dapat diketahui dari pengujian yang telah dilakukan bahwa terdapat bakteri $E$. coli pada produk tahu takwa. Hal tersebut tidak sesuai dengan SNI 01-3142-1998 tentang Tahu. Hal tersebut terjadi karena adanya proses produksi yang salah, yaitu pada proses perebusan yang menggunakan air dari bak pencucian peralatan produksi, proses pencetakan dan pengemasan yang dilakukan secara langsung tanpa menggunakan sarung tangan, serta 
pewarnaan yang juga dilakukan langsung tanpa menggunakan sarung tangan pada saat memindahkan tahu ke dalam wadah anyaman bambu.

Selain itu, terdapat bahaya pada proses pengemasan karena faktor debu dan kontaminasi bakteri dari karyawan sebagai penjamah makanan, serta serangga. Upaya yang bisa dilakukan untuk mengurangi risiko bahaya pada proses produksi adalah menggunakan air bersih yang dikhususkan untuk proses perebusan dan menggunakan sarung tangan pada saat proses produksi (Wulandari, 2012).

Hasil penelitian kimia diketahui bahwa produk tahu takwa di salah satu IRT tahu takwa di Kediri menggunakan pewarna kuning yang jumlahnya tidak dilakukan pengukuran, hanya perkiraan dari penjamah saja. Dari hal tersebut diketahui bahwa penggunaan BTP pewarna kuning Tartrazine CI 19140 dapat berbahaya bagi kesehatan karena tidak sesuai dengan PERMENKES RI No. 722 Tahun 1988 tentang Bahan Tambahan Pangan. Penambahan Tartrazine CI 19140 yang melebihi batas maksimal yang diizinkan akan menimbulkan dampak buruk bagi kesehatan baik jangka panjang, yaitu kanker maupun jangka pendek, seperti iritasi pada tenggorokan dan usus, serta keracunan. Menurut Miller (1982), pewarna kuning Tartrazine CI 19140 yang digunakan pada makanan dapat menyebabkan gejala reaksi alergi (urtikaria, rinitis, atau asma).

\section{SIMPULAN}

Berdasarkan hasil penelitian produk tahu takwa di salah satu IRT tahu takwa di Kediri, dapat ditarik kesimpulan bahwa kualitas tahu takwa menurut SNI 01-3142-1998 yang dihasilkan oleh salah satu IRT tahu takwa di Kediri terdiri dari pemeriksaan kualitas fisik, mikrobiologis, dan kimia. Pengujian dan pemeriksaan yang tidak sesuai dengan standar, antara lain pengujian mikrobiologis Escherichia coli dan Salmonella, serta pemeriksaan kimia, yaitu bahan tambahan pangan (BTP) Tartrazine CI 19140. Sedangkan pemeriksaan fisik, terdiri dari bau, warna, rasa, dan penampakan sudah sesuai dengan standar. Aspek GMP di salah satu IRT tahu takwa di Kediri termasuk dalam kategori kurang baik.

Saran yang dapat diberikan kepada industri rumah tangga agar produk tahu takwa memenuhi persyaratan SNI 013142-1998 tentang kualitas tahu adalah melengkapi label kemasan pada produk tahu takwa tentang kode produksi, tangga produksi dan kadaluarsa, dan berat bersih agar menjamin keamanan pangan yang dihasilkan, melakukan perbaikan terhadap perilaku karyawan untuk menerapkan penggunaan sarung tangan, celemek, masker, dan penutup kepala pada penjamah makanan, dan melakukan pengukuran terhadap kadar pewarna Tartrazine CI 19140 yang sesuai dengan standar sebelum ditambahkan pada saat proses pewarnaan, menyediakan tempat khusus untuk menyimpan bahan baku, bahan berbahaya, dan produk jadi agar terhindar dari debu dan hewan pengganggu.

\section{DAFTAR PUSTAKA}

Avita, Y. N., \& Dwi, Y. 2015. Analisis Kondisi Sanitasi Industri Rumah Tangga (IRT) Tape Singkong di Kabupaten Bondowoso. Artikel Ilmiah Hasil Penelitian Mahasiswa 2015. Universitas Jember. Jember.

Badan Standarisasi Nasional Indonesia SNI 01-3142-1998 tentang Kualitas Tahu.

BPS. 2016. Tabel Perkembangan UMKM pada Periode 1997-2013.

BPOM, R.I. 2008. Pengujian Mikrobiologi Pangan. Info POM Badan Pengawas Obat dan Makanan. Vol. 9 No. 2. [Online].

Koswara, S. 2006. Manajemen Pengendalian Hama dalam Industri Pangan eBookPangan.com [Online] 
Nicolas, Abdoul, Aly, Amadou, Jules, dan Alfred. 2006. Higienic Status Assessment of Dish Washing Waters, Utensils, Hands and Pieces of Monies from Street Food Processing Sites in Ouagadougou (Burkina Faso). African Journal of Biotechnology, 5(11): 1107-1112.

Peraturan Menteri Kesehatan Nomor 492 Tahun 2010 Tentang Persyaratan Kualitas Air Minum.

Peraturan Menteri Kesehatan Nomor 1096 Tahun 2011 Tentang Jasa Boga.

Peraturan Menteri Kesehatan Nomor 722 Tahun 1998 Tentang Bahan Tambahan Pangan.

Peraturan Kepala BPOM Nomor HK.03.1.23.04.12.2206 tahun 2012 tentang Cara Produksi Pangan Yang Baik Untuk Industri Rumah Tangga.

Purnawijayanti, H., 2001. Sanitasi Higiene dan Keselamatan Kerja dalam Pengolahan Makanan. Yogyakarta: Kanisius.

Rudiyanto, H., 2016. Kajian Good Manufacturing Practices (GMP) dan Kualitas Mutu pada Wingko Bedasarkan SNI-01-4311-1996. Jurnal Kesehatan Lingkungan, 8(2): 148-157.

Sari, F. N., 2016. Penerapan Good Manufacturing Practices (GMP) di Dapur Rumah Sakit. Jurnal Kesehatan Lingkungan, 8(2): 248257

Wulandari, R. 2012. Konsep Pengendalian Mutu dan HACCP (Hazard Analysis Critical Control Point) Proses Produksi Wingko Babat di Usaha Kecil Menengah "Jenang Asli" Sukoharjo. Laporan Tugas Akhir. Universitas Sebelas Maret Surakarta.

Undang - Undang Nomor 18 Tahun 2012 tentang Pangan

Rachmadia et al. 2018. Penerapan Sistem Hazard Analisis Critical Control Point (HACCP) pada Produk Ayam Bakar Bumbu Herb di Divisi Katering Diet di PT. Prima Citra Nutrindo Surabaya. Amerta Nutr (2018): 17-28 